\title{
FARKINDALIK TEMELLİ BİLIŞSEL TERAPI: Temel Felsefesi, Kavramlar, Terapötik Süreç, Eleştiriler ve Katkılar
}

\author{
Vedat Bakır 1* (D)
}

\begin{abstract}
Özet: Farkındalık temelli bilişsel terapi (Mindfulness-Based Cognitive TherapyMBCT), tekrarlayan depresyon ataklarını önlemek amacıyla farkındalık temelli stres azaltma programının (Mindfulness-Based Stress Reduction-MBSR) genişletilmesi ve bilişsel davranışçı terapi tekniklerinin birleştirilmesiyle meydana gelen etkili bir programdır. Farkındalık temelli bilişsel terapi, format olarak farkındalık temelli stres azaltma programına benzese de stresten çok depresyonu anlamaya odaklanmış bir programdır. Farkındalık temelli bilişsel terapi programı, haftada bir oturum olacak şekilde 8 hafta ve ortalama 2 saat süren bir uygulamadır. Uygulama, hem resmi meditasyon olarak nitelendirilen vücut taraması, yoga oturma ve yürüme meditasyonu gibi aktiviteleri hem de bir yaşam biçimi olarak yapılan günlük rutinleri içermektedir. Bilişsel davranışçı yaklaşımın temel ilkeleri olan "şimdi ve burada" çerçevesinde ana odaklanarak düşünce, duygu ve diğer bedensel duyumları yargılamadan ele alan bir çeşit grupla yapılan farkındalık meditasyonu uygulamaları bulunmaktadır. Oturumlarda farkındalık ve otomatik pilot, zihinlerimizde yaşamak, dağınık zihnin toplanması, beden farkındalığı, bilişsel çarpıtmalar gibi konularla birlikte kuru üzüm egzersizi, oturma ve yürüme meditasyonu ve duyumlara yönelme gibi alıştırmalar uygulanmaktadır. Programın ilk uygulama amacı kronik ağr1, depresyon, anksiyete ve stresi azaltmak olsa da zamanla koroner kalp, şeker ve kanser hastalıkları, bipolar bozukluk, kaygı bozuklukları, DEHB'li yetişkinler gibi klinik ve klinik olmayan birçok problemde etkili olduğu görülmektedir. Bu anlamda bireylerin yaşam kalitesi, iyi oluş, farkındalık, öz-şefkat, duygu düzenleme, yaşam doyumu, merhamet ve memnuniyet düzeylerinin arttırılmasında oldukça fayda sağladığı bilinmektedir. Ayrıca Mindfulness-Based Cognitive Therapy (MBCT), yapılandırılmış bir program olmasına rağmen içerik ve müdahaleleri bakımından kültürel özelliklere duyarlı esnek bir uygulama niteliği taşımaktadır.
\end{abstract}

Anahtar Kelimeler: Bilişsel-davranışçı terapi, bilinçli farkındalık, MBCT, meditasyon

\section{MINDFULNESS-BASED COGNITIVE THERAPY: Basic Philosophy, Concepts, Therapeutic Process, Criticisms and Contributions}

\begin{abstract}
Mindfulness-based cognitive therapy (MBCT) is an effective program that combines mindfulness-based stress reduction (MBSR) expansion and cognitive behavioral therapy techniques in the risk of recurrent episodes of depression. Although MBCT is similar to MBSR in format, it is a program focused on understanding depression rather than stress. The MBCT program is a practice session for 8 weeks and an average of 2 hours per week. The application includes activities such as body scan, yoga sitting and walking meditation, which are described as formal meditation, and daily routines as a lifestyle. There are mindfulness meditation practices performed with a group that deals with thoughts, emotions and other bodily sensations without judgment by focusing on the main principles of the cognitive behavioral approach, "here and now". In the sessions, exercises such as mindfulness and autopilot, living in our minds, collecting the scattered mind, body awareness, cognitive distortions, as well as dry exercise grapes, sitting and walking meditation, and orientation to sensations are applied. Although the first application purpose of the program is to reduce chronic pain, depression, anxiety and stress, over time it is seen that it is effective in many clinical and non-clinical problems such as coronary heart, diabetes and diseases, bipolar disorder, anxiety patients, ADHD. In this sense,
\end{abstract}


beneficial benefits are reported in increasing the quality of life, well-being, awareness, self-compassion, emotion regulation, life satisfaction, compassion and satisfaction levels of individuals. In addition, MBCT, according to a structured program content and content, is important in terms of content and content with other content and application content.

Keywords: Cognitive-behavioral therapy, mindfulness, MBCT, meditation

${ }^{1}$ Adres: Kütahya Dumlupınar Üniversitesi, Emet Meslek Yüksekokulu, Kütahya, Türkiye

*Sorumlu Yazar: vedat.bakir@dpu.edu.tr

Atıf: Bakır, V. (2021). Farkındalık Temelli Bilişsel Terapi: Temel Felsefesi, Kavramlar, Terapötik Süreç, Eleştiriler ve Katkılar. Bilge Uluslararası Sosyal Araștırmalar Dergisi, 5(1): 21-27.

\section{GİRIŞ}

Farkındalık temelli programlar sağlık hizmetlerinden psikoloji ve eğitim gibi bilimsel alanlara kadar geniş bir yelpazede yer edinmektedir. Bu anlamda geliştirilen ilk program olan farkındalı temelli stres azaltma programı (Mindfulness-Based Stress Reduction-MBSR), sağlık problemleri yaşayan bireylerin stres durumlarına yönelik müdahale yaklaşımı olarak kullanılmaktadır (Zümbül, 2021). MBSR, daha çok tıbbın içinde yer alırken zaman içerisinde farkındalık temelli bilişsel terapi programıyla beraber farkındalık temelli müdahaleler psikoloji alanında aktif bir şekilde kullanılmaya başlanmıştır (Kabat-Zinn, 2003). Farkındalık temelli bilişsel terapi (mindfullnessbased cognitive therapy-MBCT) sürekli olarak depresyon durumlarını yaşayan bireylerin tekrarlayan depresyon belirtilerini önlemek amacıyla geliştirilen bir eğitim programıdır (Segal vd., 2002). Farkındalık temelli bilişsel terapi farkındalık, psiko-eğitim ve etkinlik gibi bilişsel davranışçı tekniklere dayanan bir yaklaşımdır (De Raedt vd., 2012). Bu anlamda kullanılan "farkındalık" kavramı yargılamadan şimdiki ana odaklanma, deneyimlere açık olma ve kabul etme şeklinde kullanılmaktadır (Kabat-Zinn 1994). Bilişsel davranışçı yaklaşımlar, bir bireyin düşünceleri, duyguları ve davranışları arasındaki bağlantıyı ele almaktadır. Farkındalık ise bireyin benliğinin, zihinsel ve fiziksel durumlara yönelik derin farkındalığı ifade etmektedir. MBCT, geleneksel bilişsel davranışçı yaklaşımın aksine işlevsiz olan düşünceleri değiştirmek yerine tüm düşünceleri kabul ederek geçici duygu ve düşünceleri deneyimlemek amacıyla üstbilişsel bir bakış açısı öne sürmektedir. Bu doğrultuda duygu ve düşüncelere önyargısız yaklaşmak ile depresyonun nedenlerine, etkilerine ve sonuçlarına uzun süre odaklanmak birbirinden farklı görülmektedir (Nolen-Hoeksema 1991). MBCT, olumsuz düşünce ve duyguların farkına varma, yeniden düzenleme ve bireye daha geniş perspektiften bakabilme olanağ1 sunmaktadır (Mehdipour, Rafiepoor ve Haji Alizadeh, 2017). Farkındalık temelli bilişsel terapi, en çok depresyon ve diğer zihinsel bozuklukların müdahalesinde kullanılmaktadır (Dziak, 2019). Bununla birlikte bireyde var olan depresif ataklarda bir sonraki atak için oluşacak yatkınlıklara müdahale etmeyi amaçlamaktadır (Vatan, 2016). Farkındalık temelli bilişsel terapi, 2000 yılından bu yana uygulanan nispeten yeni bir grup beceri eğitimidir (Dziak, 2019). Genel olarak katılımcıların düşünce, duygu ve sağlık arasındaki ilişkiyi öğrendikleri haftalar boyunca devam eden bir eğitim programıdır. Bu program içerisinde genel bilişsel davranışçı ilkeler ile "şimdi ve burada" çerçevesinde duygu, düşünce ve davranışlara odaklanan bir çeşit meditasyon yöntemi kullanılmaktadır. Söz konusu farkındalık teknikleri kullanılarak üzüntü, korku ve endişe gibi olumsuz uyaranların ön planda olduğu depresyon ve anksiyetinin önlenmesinde geleneksel yaklaşımlara oranla daha etkili olduğu belirtilmektedir (Hunot vd., 2013). Bu kapsamda bireylerde görülen depresif belirtiler sebebiyle meydana gelen konsantrasyon bozukluklarının "şimdi ve burada" ilkesine odaklanmada problem oluşturacağı göz ardı edilmemelidir. Bundan dolayı özellikle akut dönemlerde yoğun belirtilerin görülmesi farkındalık temelli çalışmaları zorlaştıracaktır. Farkındalık temelli bilişsel terapi, akut depresyon müdahalesindeki etkililiğinden çok depresyon atakları arasındaki etkililiğiyle ön plana çıkmaktadır (Hunot vd., 2013).

Depresyon, tarih boyunca birçok insanı etkileyen, bireylerin günlük aktivitelerine ve hayatlarına olan ilgiyi kaybetmelerine neden olan ruhsal bir bozukluktur. Günümüzde ruh sağlığı uzmanları bireylerin bu zorluklarla başa çıkmalarına yardımcı olmak için çeşitli müdahale yöntemleri geliştirmektedir. Özellikle 21. yüzyılda, birçok yaklaşım bireylerin ilaç bağımlılı̆̆ını azaltarak psikolojik yöntemler kullanmaya çalışmaktadır (Vatan, 2016). Bu anlamda farkındalık temelli bilişsel terapi modern bir yaklaşım olarak kabul edilmektedir. Farkındalık temelli bilişsel terapi, düşüncelerin zihin ve beden üzerinde etkili olduğunu savunan yaklaşımlardan gücünü almaktadır (Vatan, 2016). John Teasdale ve Phillip Barnard, yirminci yüzyılın sonunda zihnin uyaranları nasıl aldığı, uyaranların duyguları ve davranışları nasıl etkilediğine yönelik etkileşimli bir bilişsel alt sistemler (ICS) modeli geliştirdiler (Dziak, 2019). Bununla beraber Jon Kabat-Zinn ise farkındalık aracılığıyla stresin azaltılmasına yönelik sekiz haftalık bir program geliştirmiştir.

Mark Williams, Zindel Segal ve John Teasdale birlikte "Farkındalık temelli bilişsel terapi" modelini oluştururken bu çalışmaları referans almışlardır (Dziak, 2019). Bundan sonra yaptıkları çalışmalarla "Farkındalık temelli bilişsel terapinin" etkililiğini ispat etmeye çalışmışlardır. 2000 yılından itibaren "Farkındalık Temelli Bilişsel Terapi" depresyon ve diğer bozukluklar için uygulayıcılar tarafından aktif bir şekilde kullanılmaya başlanmıştır.

Farkındalık temelli bilişsel terapi uygulamalarına yönelik yapılan araştırmalar 2000'li yıllardan beri giderek artmakta; tekrarlayan depresyon durumlarında ve diğer psikolojik problemlerin müdahalesinde oldukça iyi sonuçlar 
alınmaktadır (Brown ve ark. 2007 ; Chiesa ve Serretti, 2010). Jha vd. ( 2007 ) tarafından yapılan bir çalışmada farkındalık temelli stres azaltma programının dikkat alt sistemleri, uyarı, yönlendirme ve çatışmadaki etkililiği ele alınmıştır. Araştırma bulgularına göre programın uygulandığ katılımcılarda dikkat, uyarılma ve çatışma çözme becerilerinin geliştiği görülmüştür. Chambers, Lo ve Allen (2008) on günlük bir farkındalık temelli bilişsel terapi programının bireyler üzerindeki etkisini inceledikleri araştırma sonuçlarına göre programın bellek üzerinde önemli gelişmeler sağladığı; depresif belirtilerin azalması ve olumlu duyguların geliştirilmesinde etkili olduğu görülmüştür. Ortner vd. ( 2007) dikkat ve gevşeme meditasyonunun duygusal bağlamlarda dikkat kontrolü üzerindeki etkisini incelediler. $\mathrm{Bu}$ kapsamda çalışma yapılan grubun ve diğer kontrol grubunun olumsuz resimlerden duygusal anlamda etkileri karşılaştırılmıştır. Araştırma sonuçlarına göre kontrol grubunun daha olumsuz etkilendiği belirtilmektedir. Broderick ve Metz (2009) tarafından yapılan çalışmada programın duygusal düzenleme, kendini kabul, özsaygı ve öznel iyi oluşta etkili olduğu tespit edilmiştir. Bununla birlikte iyimserlik, yaşam doyumu, pozitif duygularda önemli düzeyde artış ve saldırganlık davranışlarında azalma (Schonert-Reichl ve Lawlor, 2010); kayg1, depresif belirtiler ve davranış problemlerinde ise önemli derecede bir azalma olduğu bulgusuna ulaşmıştır. Farkındalık temelli bilişsel terapi uygulamalarına yönelik yapılan çalışmaların ruhsal problemlerin müdahalesinde umut verici bir nitelikte olduğu görülmektedir. De Raedt vd., (2012) tarafindan 8 haftalık bilişsel farkındalık terapi programının etkileri deneysel grup ve kontrol grubu bağlamında incelenmiştir. Yapılan araştırmaya göre programın bireylerde depresif belirtileri önemli düzeyde azalttığı, duygusal belleği ve olumlu düşüncelerin gelişmesini sağladiğı görülmüştür.

\subsection{Temel Felsefesi}

Bilinçli farkındalık (mindfulness) kavramı oldukça eski bir tarihe dayanan bir kelime olarak günümüze kadar ulaşmaktadır (Bodhi, 2000). Özellikle Budizm öğretilerinde çok sık kullanılan bir kavram olarak görülmektedir. Bununla birlikte Yunan felsefesinden başlayıp Humanizm ve Varoluşçu felsefeye kadar çok geniş bir alanda kullanılan kavramsal bir özelliği bulunmaktadır (Brown, Ryan ve Creswell, 2007). Farkındalık temelli psikoterapi alıştırmaları ve becerileri kaynağını farkındalık temelli meditasyon uygulamalarından almaktadır (Davis ve Hayes, 2011). Bununla birlikte zaman içerisinde psikoloji alanında kullanılan bilişsel davranışçı yaklaşımlara ek olarak kullanılmaya başlanmıştır (Cash ve Whittingham, 2010). Farkındalık temelli terapi yaklaşımlarında da bilişsel davranışçı kuramın kavramları olan üstbiliş, dikkat düzenleme ve maruz bırakma mekanizmaları aktif olarak kullanılmaktadır (Çatak ve Ögel, 2010). Farkındalık temelli terapiler bilişsel davranışçı yaklaşımların "üçüncü dalgası" olarak ifade edilmektedir (Hayes, Hayes, Strosahl ve Wilson, 2006). Üçüncü kuşak terapiler, bireylerin yaşamlarında karşılaştıkları olayları değiştirmekten çok söz konusu olayların sahip olduğu işlevin anlaşılıp değiştirilmesiyle ilgilenmektedir. $\mathrm{Bu}$ nedenle bilinçli farkındalık, bireyin şimdiki zamanda gerçekleşen deneyimlerine bilerek ve isteyerek katılma becerisi gerektirmektedir (Coffey ve Hartman, 2008). Bishop vd., (2004) bilinçli farkındalık, geçmiş ve geleceğin sınırlarından çıkarak duygu ve düşüncelerin sadece şimdiki zamana odaklanması şeklinde ifade edilmektedir. Bilinçli farkındalık kaynağını başta Budizm olmak üzere yaklaşık otuz meditasyondan almaktadır. Bununla birlikte doğunun kültürel anlamda sahip olduğu perspektif ile batının klinik bakış açısını sentezlemektedir. Başlıca özelliği ise bireyin kim olduğu, kendisi ve çevresiyle ilgili algılarını sorgulamaktır.

\subsection{Kavramlar}

Farkındalık temelli bilişsel terapi, ruh sağlığı alanında kullanılan birçok yaklaşım ve uygulamayı bir arada kullanmaktadır. Bu yaklaşımların ana gövdesini ise bilişsel davranışçı terapi oluşturmaktadır (Hunot vd., 2013). Bu yaklaşım, düşünce veya davranış kalıplarının bireylerin günlük yaşamları üzerinde çok önemli bir etkiye sahip olduğu anlayışına dayanmaktadır. $\mathrm{Bu}$ nedenle bireylerin olumsuz düşünce ve davranışlarının işlevsel düşünce ve davranışlarla değiştirilerek genel işleyişin geliştirilebileceğini savunmaktadır.

Bilinçli farkındalık uygulamalarına daha çok netlik kazandıran merkezsizleştirme, otomatik pilot ve zihin uçuşması kavramlarıdır. Merkezsizleştirme, bireyin duygu ve düşüncelerini bir sinema perdesinde izliyormuş gibi olumlu ve olumsuz herhangi bir yargılamada bulunmamasını ifade etmektedir (Safran ve Segal, 1990). Kavramın temelinde duygu ve düşüncelerin geçici olduğunu kabullenme yatmaktadır. Otomatik pilot, bilinçli yapılmayan davranışları, bir nevi bilinçli farkındalığın zıttı olarak kullanılan bir kavramdır (Segal vd., 2002). Bireyin zihninin meşgul olduğu durumlarda yaptığı rutin işlerin süreci hakkında bir farkındalığının olmaması bu duruma örnek olarak gösterilebilir. Zihin uçuşması ise bireyin zihninin sürekli olarak geçmiş yaşantılar ve gelecek zamanla meşgul olması şimdiki ana odaklanamaması olarak ifade edilmektedir (Raichle, MacLeod, Snyder, Powers, Gusnard ve Shulman, 2001). Zihin uçuşması, bireyin otomatik moda geçerek günlük yapılan rutin işleri üzerinde düşünmeye ihtiyaç duymadan yapmasını sağlayan bir yapıya sahiptir.

Farkındalık temelli bilişsel terapiyi geliştiren araştırmacılar insan zihninin bilgiyi farklı şekillerde işlediğini öne sürmektedir. Bilgiyi işlemenin temelde iki ana yöntemi "olma modu (being mode)" ve "yapma modu (doing mode)" olduğunu belirtmektedirler (Dziak, 2019). İnsanlar günlük yaşamlarındaki ihtiyaçlarına göre doğal olarak bu iki mod arasında geçiş yapmaktadırlar. Bununla birlikte modlar arasındaki geçişte yaşanan zorluklar psikolojik problemlere neden olmaktadır. Farkındalık temelli bilişsel terapi uygulayıcıları kısa vadeli ve sık değişen yapma modundan ziyade uzun vadeli özelliklere sahip olan olma moduna teşvik ederler. $\mathrm{Bu}$ nedenle, kalıcı zihinsel ve duygusal değişiklikler en iyi şekilde olma modu aracılığıyla kullanılmaktadır. Farkındalık temelli bilişsel terapinin temel unsurlarından bir diğeri de farkındalıktır. Farkındalık kavramına yönelik tanımlar birbirinden farklı olsa da genellikle araştırmacılar farkındalığı bir bireyin zihninde ve bedeninde gerçekleşen süreçlere ilişkin "derin farkındalık" olarak kabul ederler. Farkındalık kavramına dayanan terapiler, bireyi çok yönlü tanıyarak olumlu düşünceler ve eylemler aşılamayı amaçlamaktadır (Collard, 2013).

Farkındalık temelli bilişsel terapi, depresyon ve diğer bozuklukların daha çok yorgunluk, kötü ruh halleri veya olumsuz düşüncelerin eşlik ettiği durumlarda ortaya çıktığını 
savunmaktadır. Uzun süreli ve ciddi anlamda depresyon yaşayan insanlarda genellikle bu faktörleri birbiriyle etkileşim halindedir. $\mathrm{Bu}$ anlamda yapma modu, olma modunu bastırmaktadır (Hunot ve ark. 2013). Farkındalık temelli bilişsel terapi yardımıyla bireyler geçiş faktörlerinden etkilenmeden "olma modu" ile hayata yeniden bağlanmaya, karakterlerini ve değerlerini görmeye başlarlar. Bu doğrultuda bireyler düşünce ve duygularından bağımsız bir şekilde yaşamlarını tehdit eden zararlı duygu ve davranışları tanıyabilirler. Bireyler olumsuz düşünceler ve davranışlar yerine olumluya odaklanarak muhtemel tehlikelerin oluşmasına yönelik önleyici tedbirler alabilmektedir.

\subsection{Terapötik Süreç ve Teknikler}

Farkındalık temelli bilişsel terapi, yargılayıcı olmak yerine kabul edici bir tavır sergileyerek bireylerin şimdiki ana odaklanmaları gerektiğini ifade etmektedir (Segal vd., 2012; Teasdale vd., 2000 ). Farkındalık becerileri yardımıyla bireylerin dikkatini artırmak, sıkıntı verici duygu ve düşünceler için farklı stratejiler uygulamalarını öğretmeye çalışmaktadır (Segal vd., 2012 ). Deneysel uygulamalar yoluyla bireylerde bir meta-farkındalık oluşturarak geri adım atmayı veya ilk düşüncelerinden kopmayı öğretir; böylelikle tekrarlayan olumsuz düşünceye karşı koyarak bilişsel esnekliği artırmaktadır (Kuyken vd., 2010; Segal vd., 2012; Van Der Valderen vd., 2015). MBCT, kişinin çevresine uyarlanabilir ve esnek yanıt vermesini artıran, depresyonla ilişkili olumsuz otomatik bilişler silsilesinden korumaya yardımcı olmaktadır (Shapiro vd., 2006 ).

Segal, Williams ve Teasdale $(2002,2012)$ farkındalık temelli bilişsel terapi uygulamaları için yol haritası niteliğinde olan sekiz oturumluk bir program önermektedir. MBCT'nin her oturumunda beş değişim aracı olan protokol, farkındalık uygulamaları, bireysel öğrenme, grup süreci ve somutlaşmış bilinçli varlığı ile tema, gerekçe, niyet ve uygulama becerilerinden (TRIP) kullanılmaktadır (Woods, Rockman ve Collins, 2016). Program kapsaminda sunulan bu çerçeveler grup sürecinde öğretimin kapsamını keşfetmek, uygulamaları güçlendirmek ve katılımcılara aradıkları değişiklikleri başarmalarında yardımcı olmak için organize bir yaklaşım sunmaktadır. Bu sayede katılımcıların endişe düzeyleri kontrol altına alınarak programın temel yönlerine derinleşmeye yardımcı olmaktadır. MBCT, sekiz hafta boyunca uygulanan bir grup programı olarak sunulmaktadır. MBCT programı, bilinçli farkındalık ve bilişsel davranış terapisinin bir arada kullanılmasıyla oluşan deneyimsel bir öğretim ve öğrenim biçimini vurgulamaktadır (Woods, Rockman ve Collins, 2019). Farkındalık temelli bilişsel terapinin amacı, bireylere psikolojik problemler ile mücadele etmelerinde gerekli olan becerileri kazandırmaktır. $\mathrm{Bu}$ doğrultuda programının ilk yarısı, dikkat ve farkındalığı sabitlemeye ve güçlendirmeye odaklanır. Bu temele dayanan ikinci yarıda ise katılımcılara zihinsel bozukluklara karşı yardımcı olacak öğrenmeleri kolaylaştıran çeşitli farkındalık uygulamaları ve bilişsel egzersizler sağlar (Woods vd., 2019). Buradaki asıl mantık depresyona karşı savunmasız olan insanlar için tetikleyici nitelikte olan düşünme biçimlerini belirleyerek iyilik düzeyinin artmasına yönelik çeşitli beceriler kazandırmaktır. Bireyler istenmeyen bir durumla karşılaştıklarında yaygın olarak inkâr, endişe, kaçınma veya dikkat dağıtma gibi işlevsel olmayan yöntemler kullanılmaktadır (Woods vd., 2019). Bu program ise katılımcıların düşük ruh hali ve olumsuz düşünce kalıplarına yönelik farklı bir ilişki geliştirmelerini sağlamayı amaçlamaktadır.

Farkındalık temelli bilişsel terapi uygulayıcıları sekiz haftalık bir danışma programı planlamaktadır (Hunot ve ark. 2013). Yaklaşık iki saat süren programlar esnasında katılımcılara bir farkındalık alıştırılması öğretilerek süreç başlatılır ve ardından deneyimlerin sorgulandığı tartışma aşaması gerçekleştirilir. Sorgulama sürecinde stresi azaltmak, depresyonun tekrarlamasını önlemek ve iyi kalmak için farkındalıkların vurgulandığı bir "şimdiki an" odağı vardır (Segal vd., 2012). Ayrıca oturumların çoğunda, o haftanın temasıyla ilgili olan ve düşüncelerin ruh halini ve davranışı nasıl güçlendirdiğine dair bir araştırma içeren bilişsel bir egzersiz yer almaktadır. Farkındalık temelli bilişsel terapi protokolünün bir özeti aşağıda açıklanacaktır.

\section{Sekiz oturumluk program}

Farkındalık temelli bilişsel terapi programına başlamadan önce bireysel olarak ya da grup yoluyla bir ön görüşme yapılmaktadır. Katılımcılara "Farkındalık Temelli Bilişsel Terapi” hakkında genel bir bilgi verilerek faydaları ve olası riskleri aktarılmaktadır. $\mathrm{Bu}$ doğrultuda bireyler programa katılmanın sıkı bir çalışma ve sabır gerektirdiğini öğrenmektedirler (Woods vd., 2019). Ayrıca katılımcıların depresyon deneyimleri ve programla ilgili soruları cevaplandırılarak genel bir tarama özelliği taşıyan bir görüşme yapılmaktadır.

"Farkındalık ve otomatik pilot" temalı birinci oturumda katılımcılar tanışır ve grup kuralları belirlenerek program hakkında kısaca bilgi verilir. Daha sonra katılımcılara iki farkındalık uygulaması öğretilir. Birincisi, "kuru üzüm uygulaması", normal şartlar altında bireyin anında yapacağı bir eylemi ağır ağır yapması istenir (Woods vd., 2019). İkincisi ise farkındalık temelli bilişsel terapide temel bir beceri kabul edilen "vücut taraması meditasyon uygulaması" yoluyla bedene odaklanmadır. Bu şekilde her uygulamadan sonra katılımcıların sürece ilişkin görüşleri alınır ve ev ödevi verilerek oturum sonlandırılır (Segal vd., 2002). Ev ödevinde genellikle ses kaydı kullanılarak vücut tarama meditasyonu ve günlük yapılan rutin, basit işlerde bile şimdiki ana odaklanma alıştırmalarının yapılması istenmektedir.

İkinci oturum olan "zihinlerimizde yaşamak" temasında beden taraması meditasyon uygulaması ve ev ödevleri gözden geçirilmektedir (Woods vd., 2019). Ardından bilişsel bir egzersiz yapılarak on dakikalık oturma meditasyonuna geçilir. Son olarak gelecek haftanın ev ödevi verilerek oturum sonlandirılmaktadır.

Üçüncü oturum olan “dağınık zihnin toplanması" temasında beş dakikalık bir görme veya işitme meditasyonu ile başlamaktadır. Ardından nefes ve beden farkındalığına yönelik otuz dakikalık oturma meditasyon uygulamasına geçilir ve sonrasında sürece ilişkin yorumlar yapılır (Woods vd., 2019). Grup lideri tarafından bir önceki hafta verilen ev ödevleri gözden geçirilir. Son olarak üç dakikalık nefes alanı uygulaması ve dikkatli hareket uygulaması yapılarak bir sonraki ev ödevi verilmektedir.

Dördüncü oturum olan "nefreti fark etmek" teması beş dakikalık bir görme veya işitme meditasyonu ile 
başlamaktadır. Nefes, beden, ses, düşünce ve duygulara ilişkin otuz ile kırk dakika sürecek bir oturma meditasyonu ile devam eder. Bir şiir okunarak beyin firtınası yapılır (Woods vd., 2019). Ev ödevleri kontrol edilerek "otomatik düșünceler anketi” uygulanır. Son olarak üç dakikalık nefes alanı uygulaması, dikkatli hareket uygulaması ve depresyon "bölgesi” gözden geçirilerek ev ödevi verilmektedir.

Beşinci oturum olan "izin verme" teması endișeleri ortaya çıkaracak olan otuz ile kırk dakikalık oturma meditasyonu ile başlar. $\mathrm{Bu}$ uygulama kapsamında endişe durumlarının beden üzerindeki etkisi üzerine konuşulur. Bir önceki hafta verilen ev ödevleri kontrol edilir (Collard, 2013). Son olarak üç dakikalık nefes alanı uygulaması ve dikkatli hareket uygulaması yapılarak bir sonraki ev ödevi verilir.

Altıncı oturum “düşünceler gerçek değildir" teması çerçevesinde nefes, beden, ses, düşünce ve duygulara ilişkin otuz ile kırk dakika sürecek bir oturma meditasyonu ile başlar. Düşüncelerin gerçek olmadığına yönelik bilişsel alıştırmalar yapılarak alternatif düşüncelere bir yönlendirme yapılır (Woods vd., 2019). Bir önceki haftanın ödevleri kontrol edilir. Bireyin çarpıtılmış düşünceleri bilişsel alıştırmalar yoluyla ortaya çıkarılır. Son olarak ise ev ödevi verilmektedir.

Altıncı oturumdan sonra katılımcılar "tüm gün sessiz inziva" temasiyla bir araya gelmektedir. $\mathrm{Bu}$ kapsamda beden taraması, dikkatli hareket, yürüme ve oturma meditasyonu gibi çeşitli uygulamalar kullanılmaktadır. Aynı zamanda yemekle ilgili tüm hisleri fark etmek için öğle yemeği için verilen arada bu sürece dâhil edilir. Bu sayede otomatik olarak gerçekleşen yemek yeme davranışında çok fazla dikkat etmediğimiz görme, tat, koku alma, duyma ve dokunma deneyimlerinin gelişmesine firsat tanınmış olur. Tüm gün sessiz inziva uygulamasının nedeni, anlık bir dikkat etkileşimini desteklemek ve geniş bir çerçeve sağlamaktır (Woods vd., 2019).

Yedinci oturum "kendime en iyi nasıl bakabilirim?" teması çerçevesinde nefes, beden, ses, düşünce ve duyguların ilişkileri ve beden üzerindeki etkilerini fark etmeye ilişkin otuz ile kırk dakika sürecek bir oturma meditasyonu ile başlar (Vatan, 2016). Bir önceki haftanın ödevleri kontrol edilir. Bilişsel alıştırmalar uygulanır ve bireysel eylem planı oluşturulur. Son olarak ise ev ödevi verilir.

Sekizinci oturum "yeni öğrenmeyi sürdürmek ve genişletmek" teması çerçevesinde bir beden tarama meditasyonu ile başlar. Sekiz haftanın genel bir değerlendirilmesi yapılır. Önceki hafta hazırlanan bireysel eylem planı tekrar gözden geçirilerek program sonlandırılır. Katılımcılar haftalık olarak gerçekleştirilen programların yanı sıra çeşitli alıştırma derslerine de katılabilirler (Segal vd., 2002). Bu alıştırma eğitimlerinden bazıları, insanların hızlı ve kolay bir şekilde gerçekleştirebilecekleri bedenin ve zihnin durumuna yönelik üç dakikalık nefes egzersizleri gibi günlük yapılan uygulamalardır (Hunot ve ark. 2013).

\section{Temalar, Gerekçe, Niyet, Uygulama Becerileri (TRIP)}

Woods 2013 ' te MBCT' nin uygulanmasında ek yapılara ihtiyaç olduğunu düşünerek temalar, gerekçe, niyet ve uygulama becerileri (TRIP) formatını geliştirdi (Woods vd., 2019). $\mathrm{Bu}$ format her oturumun temalarının, konusunun, ortamının ve bağlamının net bir șekilde anlaşılmasını içermektedir. Ayrıca uygulama için belli bir mantık çerçevesinde neyin öğretildiği, nasıl öğretildiği ve amaca yönelik adımların nasıl sağlanacağı konusunda katılımcılara beceri öğretimi sağlamaktadır. $\mathrm{Bu}$ anlamda TRIP'in bu unsurları program boyunca netlik ve derinlik sunan bir pusulayı temsil etmektedir. Temalar, katılımcıların öğrenmesinin sürekliliğini ve modülerliğini sağlayarak önemli ve özgül konuların oturumlarda işlenmesini sağlamaktadır (Woods vd., 2019). Oturumlarda işlenen konuların organize edilmesi önemli görülmekle birlikte öğretilen şeylerin gerekçelendirilmesi ve katılımcıların bu gerekçelerin farkında olması da gerekmektedir. Katılımcıların öğretilen becerilerin ve yapılan uygulamaların niçin yapıldığının gerekçeleriyle farkında olmaları süreci anlamlı kılmaktadır. Niyetler, haftalık yapılan oturumların amacını ele almaktadır. Bu kapsamda yapılan etkinliklerde beş duyu ile beraber düşünme kullanılarak uygulamanın amacına hizmet etmesi sağlanmaktadır. Uygulama becerileri ise oturumlarda uygulanan uygulamaların ve alıştırmaların belirlenmesi ve bunların nasıl uygulanacağına yönelik gerekli yeterliliğe sahip olmaktır (Woods vd., 2016).

Meditasyon uygulamalarını bilişsel davranış egzersizleriyle bir araya getiren MBCT programı, bilişsel değerlendirme, algılama, yorumlama ve farkındalık becerilerinin ruh haline etkisi bakımından sağlam bir temel ve yapı sunmaktadır.

\section{KATKILARI VE SINIRLILIKLARI}

MBCT programı, meditasyon uygulamaları aracılığıyla farkındalığ 1 sağlamak için yürüme, oturma ve çeşitli yoga pozlarına dayanan hareket uygulamalarını içermektedir. Bunun dışında sistematik olmayan uygulamalar aracılığıyla da bireylerin farkındalık anlamında pratik yapmalarına destek olmaktadır. Günlük yaşam içerisinde yemek ve temizlik yapmak, bulaşık yıkamak, çöpü çıkarmak gibi bir dizi rutin aktiviteleri farkındalık bağlamında kullanabilmeyi teşvik etmektedir. Gerçek dünyadaki olayların etkileşimlerini birbiriyle ilişkilendirerek ruh halinin düzenlenmesinde önemli ve temel becerilerin geliştirilmesine olanak tanımaktadır. Bireylerin yaşamın sıradan görevlerine bilinçli bir farkındalık geliştirmelerini sağlayarak deneyimsel alanda duygusal durum ve düşünce kalıplarını öğretmektedir.

\section{SONUÇ VE ÖNERİLER}

Farkındalık temelli bilişsel terapi uygulama alanında daha yeni olduğu için uzun vadeli etkileri çok fazla bilinmemektedir. Bununla beraber bazı araştırmacılar tarafından kontrol gruplarının eksikliği ve katılımcıların küçük örnek boyutları sebebiyle eleştirilmektedir. Birçok araştırmacı ise farkındalık temelli bilişsel terapinin depresyon ve anksiyete başta olmak üzere birçok problemde oldukça başarılı olduğunu öne sürmektedir (Segal vd., 2012; Collard, 2013; Woods vd., 2016). Ayrıca bipolar bozukluk, yeme bozuklukları, kalp hastalığı, kronik ağrı ve kanser gibi bazı fiziksel bozukluklar yaşayan insanlara da fayda sağladığı düşünülmektedir (O'Doherty vd., 2015; Dziak, 2019). Farkındalık Temelli Bilişsel Davranışçı Terapi ile bireyler kendilerine yönelik eleştirel ve yargılayıcı olmak yerine deneyimlere karşı açık, ilgili, kabul edici, şefkatli ve sıcak bir duruş geliştirmektedirler (Ögel, 2015). İlgili 
literatürde bu terapi yöntemine ilişkin birçok araştırma yapılarak etkinliğine ilişkin çok sayıda sonuç elde edilmiştir. Farkındalık temelli bilişsel terapi, deneysel araştırmalar yoluyla birçok alanda farklı yaş gruplarına uygulanan ve etkililiği bilimsel anlamda kabul görmüş olan bir yaklaşımdır. $\mathrm{Bu}$ anlamda Türkiye'de bu yaklaşımın uygulanması, araştırılması ve toplumsal yapımıza yönelik değerlendirmenin yapılması önerilmektedir.

\section{KAYNAKLAR}

BISHOP, S. R.,LAU, M., SHAPIRO, S., CARLSON, L., ANDERSON, N. D., CARMODY, J., SEGAL, Z.V., ABBEY, S., SPECA, M., VELTING, D. VE DEVINS, G. (2004). Mindfulness: A proposed operational definition. Clinical psychology: Science and practice, 11(3), 230- 241.

BODHI, B. (2000). A comprehensive manual of Abhidhamma. Seattle, WA: Buddhist Publication Society Pariyatti Editions.

BRODERICK, P.C. ve METZ, S. (2009). Learning to BREATHE: A pilot trial of a mindfulness curriculum for adolescents. Advances in School Mental Health Promotion, 2(1), 35-45.

BROWN, K. W., RYAN, R. M., ve CRESWELL, J. D. (2007). Mindfulness: Theoretical foundations and evidence for its salutary effects. Psychological Inquiry, 18, 211-237.

CASH, M., ve WHITTINGHAM, K. (2010). What facets of mindfulness contribute to psychological well-being and depressive, anxious, and stress-related symptomatology? Mindfulness, 1(3), 177-182.

CHIESA, A., ve SERRETTI, A. (2010). A systematic review of neurobiological and clinical features of mindfulness meditations. Psychological Medicine, 40, 1239-1252.

CHAMBERS, R., LO, B. C. Y., ve ALLEN, N. B. (2008). The impact of intensive mindfulness training on attentional control, cognitive style, and affect. Cognitive Therapy and Research, 32, 303-322.

COFFEY, K. A., ve HARTMAN, M. (2008). Mechanisms of action in the inverse relationship between mindfulness and psychological distress. Complementary health practice review, 13(2), 79-91.

COLLARD, P. (2013). Mindfulness-based cognitive therapy for dummies. ProQuest Ebook Central https://ebookcentral.proquest.com

ÇATAK, P., ve ÖGEL, K. (2010). Farkındalık temelli terapiler ve terapötik süreçler. Klinik Psikiyatri(13), 85-91.

DAVIS, D. M., HAYES, J. A. (2011). What are the benefits of mindfulness? A practice review of psychotherapy - related research. Psychotherapy, 48(2), 198.

DE RAEDT, R., BAERT, S., DEMEYER, I. et al. (2012). Changes in Attentional Processing of Emotional Information Following Mindfulness-Based Cognitive Therapy in People with a History of Depression: Towards an Open Attention for all Emotional Experiences. Cogn Ther Res 36, 612-620. https://doi.org/10.1007/s10608-011-9411$\mathrm{X}$
DZIAK, M. (2019). Mindfulness-based cognitive therapy (MBCT). Salem Press Encylopedia of Health.

HAYES SC, S. K., HAYES, S., Strosahl, K., W, ve Wilson, K. (1999). Acceptance and commitment therapy: An experiential approach to behavior change. New York: Guilford Press.

HUNOT V, MOORE TH, CALDWELL DM, FURUKAWA TA, DAVIES P, JONES H et al. (2013) 'Third wave' cognitive and behavioural therapies versus other psychological therapies for depression. Cochrane Database Syst Rev, 10:CD008704

JHA, A. P., KROMPINGER, J., ve BAIME, M. J. (2007). Mindfulness training modifies subsystems of attention. Cognitive Affective ve Behavioral Neuroscience, 7, 109-119.

KABAT-ZINN, J. (1994). Wherever you go, there you are: Mindfulness meditation in everyday life. New York: Hyperion.

KABAT-ZINN， J. (2003). Mindfulness-based interventions in context: Past, present, and future. Clinical Psychology: Science and Practice, 10(2), 144-153. DOI: 10.1093/ clipsy/bpg016

MEHDIPOUR F, RAFIEPOOR A, HAJI ALIZADEH K. (2017). Kanser Hastalarında Negatif Otomatik Düşünceleri ve İşlevsiz Tutumları Azaltmada Farkındalık Temelli Bilişsel Grup Terapisinin Etkinliği, Zahedan J Res Med Sci.19(6): e10609. doi:10.5812/ zjrms.10609.

NOLEN-HOEKSEMA, S. (1991). Responses to depression and their effect on the duration of depressive episodes. Journal of Abnormal Psychology, 100, 569-582.

O'DOHERTY, V., CARR, A., MCGRANN, A., O'NEILL, J. O., DINAN, S., GRAHAM, I., VE MAHER, V. (2015). A controlled evaluation of mindfulness-based cognitive therapy for patients with coronary heart disease and depression. Mindfulness, 6(3), 405-416.

RAICHLE, M. E., MACLEOD, A. M., SNYDER, A. Z., POWERS, W. J., GUSNARD, D. A., \& SHULMAN, G. L. (2001). A default mode of brain function. Proceedings of the National Academy of Sciences, 98(2), 676-682.

SAFRAN, J. D., ve SEGAL, Z. V. (1990). Cognitive therapy: An interpersonal process perspective. New York, NY: Basic.

SCHONERT-REICHL, K. A. ve LAWLOR, M. S. (2010). The effects of a mindfulnessbased education program on pre-and early adolescents' well-being and social and emotional competence. Mindfulness, 1(3), 137- 151.

SEMPLE, R. J., LEE, J., ROSA, D., ve MILLER, L. F. (2010). A randomized trial of mindfulness-based cognitive therapy for children: Promoting mindful attention to enhance social-emotional resiliency in children. Journal of Child and Family Studies, 19(2), 218-229.

SEGAL, Z., WILLIAMS, M., ve TEASDALE, J. (2002). Mindfulness-based cognitive therapy for depression: A new approach to preventing relapse. New York: Guilford Press.

SEGAL, Z. V., WILLIAMS, J. M. G., ve TEASDALE, J. D. (2012). Mindfulness-based cognitive 
therapy for depression. ProQuest Ebook Central https://ebookcentral.proquest.com

SHAPIRO, S. L., CARLSON, L. E., ASTIN, J. A., ve FREEDMAN, B. (2006). Mechanisms of mindfulness. Journal of Clinical Psychology, 62(3), 373-386.

TEASDALE, J. D., SEGAL, Z. V., WILLIAMS, J. M. G., RIDGEWAY, V. A., SOULSBY, J. M., ve LAU, M. A. (2000). Prevention of relapse/recurrence in major depression by mindfulness-based cognitive therapy. Journal of Consulting and Clinical Psychology, 68, 615-623.

ORTNER, C. N. M., KILNER, S. J., ve ZELAZO, P. D. (2007). Mindfulness meditation and reduced emotional interference on a cognitive task. Motivation and Emotion, 31, 271-283.

ÖGEL, K. (2015). Farkındalık (mindfulness) temelli bilişsel davranışçı psikoterapiler. Turkiye Klinikleri Psychiatry - Special Topics, 8(2), 28-32. https://www.turkiyeklinikleri.com/article/en-farkindalikmindfulness-temelli-bilissel-davranisci-psikoterapiler71494.html

VAN DER VELDEN, A. M., KUYKEN, W., WATTER, W., et al. (2015). A systematic review of mechanisms of change in mindfulness-based cognitive therapy in the treatment of recurrent major depressive disorder. Clinical Psychology Review, 37, 26-39.

VATAN, S. (2016). Bilişsel Davranışçı Terapilerde Üçüncü Kuşak Yaklaşımlar- Third Wave of Cognitive Behavioral Therapies. Psikiyatride Güncel YaklaşımlarCurrent Approaches in Psychiatry, 8(3), 190-203. https://doi.org/10.18863/pgy.238183

WOODS, S. L., ROCKMAN, P., ve COLLINS, E. (2016). A Contemplative dialogue: The inquiry process in mindfulness-based interventions. Toronto, Canada: Centre for Mindfulness Studies. Retrieved from https://slwoods.com/wpcontent/uploads/2016/02/acomplent ativedialogue-2-2012.pdf

WOODS, S. L., ROCKMAN, P., ve COLLINS, E. (2019). Mindfulness-Based Cognitive Therapy: Embodied Presence and Inquiry in Practice. Oakland, CA: Context Press.

http://search.ebscohost.com/login.aspx?direct=truevedb=e0 00xtrvean $=1907846$ velang $=$ trvesite $=$ ehost-live

ZÜMBÜL, S. (2021). Bilinçli farkındalık temelli bilişsel terapi: bir inceleme çalışması. İstanbul Aydın Üniversitesi Sosyal Bilimler Dergisi, 13(1), 155-194. 